\title{
CLEANLINESS EFFICACY OF NEOLIX AND SILK ROTARY SYSTEMS IN ROOT CANAL RETREATMENT
}

\author{
Mohamed I. Rabie *, Hayam Y. Hassan ** and Elham I. Elshaboury ${ }^{* * *}$
}

\begin{abstract}
Aim: Comparing the cleanliness efficacy of Neolix and Silk nickel-titanium rotary systems used in root canal retreatment with and without Carvene solvent. Method: Forty extracted maxillary anterior teeth having single root canal were collected. Root canals were prepared and obturated with size 40 gutta-percha and Guttaflow bioseal, bioactive sealer. The root canals were distributed into two groups stated to the method of obturating material removal using (Neolix and Silk file systems). Further the groups were subdivided into two subgroups by using Carvene as a solvent or not. Roots were separated in bacco-lingual direction into two equal halves then cleanliness was analyzed using Stereomicroscope at the cervical, middle and apical regions. Results: Neolix system recorded higher cleanliness than Silk file system. Treatment with no-solvent recorded higher cleanliness than with using Carvene. Cervical region recorded the highest cleanliness followed by middle then apical region. Conclusion: Neolix file system without using solvent were more efficient for removing root canal obturating materials.
\end{abstract}

KEYWORDS: Neolix, Silk, Carvene, Retreatment, Stereomicroscope

\section{INTRODUCTION}

Root canal retreatment mainly achieve the health of periapical tissue in order to promote long-term tooth survival. Therefore, elimination of obturating material, instrumentation of the root canals then reobturate them is essential ${ }^{(1)}$. Removal of obturating materials in a short time for non-surgical retreatment requires an ideal instrument, not only to clean the canal with no debris extrusion or root canal shape modification but also with no instrument separation or any unfavorable events ${ }^{(2,3)}$.

The techniques used to remove obturating materials from all the canals involve hand instruments ${ }^{(4,}$ ${ }^{5)}$, ultrasonics ${ }^{(6)}$, lasers ${ }^{(7)}$, and heat-carrying instruments ${ }^{(8)}$ and nickel titanium $(\mathrm{NiTi})$ rotary instruments ${ }^{(9)}$.

Endodontic rotary NiTi files have been used with or without gutta-percha solvents saving time

* Assistant Professor of Endodontic, Faculty of Dentistry, Suez Canal University, Ismailia, Egypt.

** Associated Professor of Endodontic, Faculty of Dentistry, Suez Canal University, Ismailia, Egypt.

*** Associated Professor of Endodontic, Faculty of Dentistry, October University for Modern Sciences and Arts

(MSA), Giza, Egypt. 
wanted to remove the obturating materials from root canal ${ }^{(10)}$.

Recently, Neolix single-file rotary system was introduced to the market. Neoniti A1 has continuous rotating movement and is made up of special alloy that permits the file flexibility. It has a non-uniform square or rectangular cross-section along the blades, which confers optimal flexibility to the file. Also, in contrast to other NiTi files, Neolix can be precurved. It has a non-cutting tip and provides easy and safe access to the apex. It enables efficient instrumentation of root canal with only one rotary NiTi file ${ }^{(11)}$.

Mani Silk are NiTi alloy of martensitic type makes the file more flexible to accommodate the stress. Files are heat treated from D1 to D10 of the cutting flutes providing increased fracture resistance and flexibility. The cross-section is teardrop shaped. This design channels debris out of the canal efficiently and centers the file while minimizing transportation. This teardrop cross-section also decreases the "screwing-in" effect and simultaneously improves tactile sensation. The Mani Silk files have a constant taper throughout the file length with noncutting tip ${ }^{(12)}$.

Carvene is d-limonene based liquid used as gutta percha solvent for root canal retreatment ${ }^{(13)}$.

This study aimed to assess the cleanliness ability of Neolix and Silk nickel-titanium rotary systems used in root canal retreatment with and without Carvene solvent using the stereomicroscope evaluation.

\section{METHODS}

Forty extracted human mandibular premolar teeth with single root canals with mature apex were collected. Teeth with cracks or fracture lines were eliminated after examination using loops. The teeth were cleaned and stored in saline solution.

\section{Root canal preparation}

All teeth crowns were removed to gain uniform working length of $17 \mathrm{~mm}$ from the apex using a diamond disk (D\&Z, Darmstadt, Germany). The root canals working length were adjusted using size $10 \mathrm{~K}$-file (Dentsply, Maillefer) which was introduced passively into each canal and subtracting $1 \mathrm{~mm}$ from the end of the apex.

The coronal part of each canal was widening using Gates-Glidden drills sizes \# 4, 3 and 2. Then apical preparation was completed with K-type files (Dentsply Maillefer) to an apical size $\# 40$. $2.5 \% \mathrm{NaOCl}$ was supplied with a 30 -gauge needle involving each succeding file size. $5 \mathrm{ml}$ of 17\% EDTA aqueous solution were used for $3 \mathrm{~min}$ followed by $5 \mathrm{ml}$ of $2.5 \% \mathrm{NaOCl}$.

The Guttaflow bioseal is (Coltène/Whaledent AG, Altstatten, Switzerland) a bioactive epoxy resin based sealer supplied in $5 \mathrm{ml}$ auto-mix syringe. Gutta-percha master cone 40/0.02 (Dentsply/Tulsa; Tulsa, Okla) was picked. Next, master cone coated with sealer was pointed up to the working length. Obturation was completed lateral compaction. Each tooth was radiographed ensure consistency of obturation. Teeth were incubated at $100 \%$ humidity at $37^{\circ} \mathrm{C}$ for 7 days to permit setting of sealer.

\section{Grouping of samples}

Specimens were divided randomly into 2 main equal groups (each=20) according to the instrument used in removal of the root canal obturating materials

For group 1: Neolix (Neolix, châtres-la-Forêt, France) was used according to the manufacturer's instructions until elimination of the obturating material to the full working length. As the instrument advanced inside the root canal, it was removed and cleaned with sterile gauze. The CXSmart endodontic motor (Dentsply/Tulsa; Tulsa, Okla) together with the Neolix system (C1:25/0.12, A1:40/0.04) that are recommended to be used with 
speed of 300 to $500 \mathrm{rpm}$ and torque limit of 1.5 $\mathrm{N} / \mathrm{cm}$. Neoniti $\mathrm{C} 1$ was introduced into the canal at a maximum depth $5 \mathrm{~mm}$ then Neoniti A1 was employed till reach the full working length.

For group 2: Silk (Mani, Japan) was used coronal started with $25 / 0.08$ as orifice opener. Then 30/0.04 and 35/0.04 followed by 40/0.04). The files used at rotational speed of $500 \mathrm{rpm}$ with a torque value of $300 \mathrm{~g} / \mathrm{cm}$ until reach the full working length.

Then, each group was further subdivided into two subgroups $a$ and $b(n=10)$ corresponding to using Carvene (Industrial Estate, Diglana, Jammu, India) as a solvent or not in-combination with the retreatment instrument.

The first two subgroups 1a and 2a: the obturating material were removed using the removal system as mentioned before in-combination with few drops $(0.1 \mathrm{ml})$ of Carvene solvent. A drop of Carvene was applied at the canal opening by insulin syringe and left for 2 minutes for solvent penetration.

The second two subgroups $1 \mathrm{~b}$ and $2 \mathrm{~b}$ : the obturating material was removed using the removal system as mentioned before without using any solvent.

During retreatment, each canal was irrigated with $1 \mathrm{ml}$ of freshly prepared $2.5 \%$ sodium hypochlorite after each file used. All instruments were cleaned regularly. Preparation was seemed complete when there was no root obturating material or sealer covering the instruments and when the irrigating solution become clear of debris.

\section{Cleanliness evaluation of the root canal walls us- ing Stereomicroscope:}

Cleanliness of the root canals after removal of obturating material was evaluated using Stereomicroscope (Scope capture, China). Grooves parallel to the long axis were made on the buccal and lingual surfaces of all the roots and were cut into two halves using diamond disks then split completed using chisel. The cleanliness percentage was evaluated at the cervical, middle, and apical thirds.

The total areas of each third was defined, and the percentage of the area covered by obturating material remnants was calculated. Images of each section were made by USB Stereomicroscope attached to IBM computer at the X30 magnification to give clear vision of canals. The debris present in the canals was bordered. Image $\mathbf{J}$ software (National Institutes of Health, v1.39a) was used to calculate the surface area of the root canal third and the debris exist as shown in Figure (1).

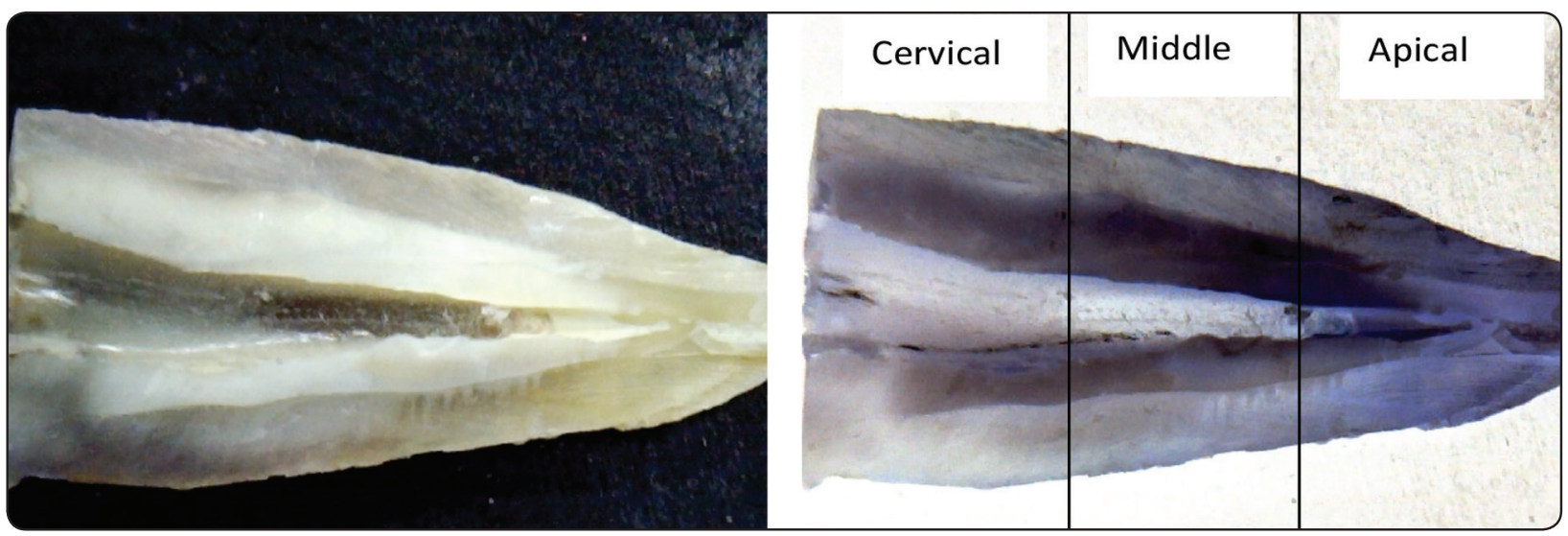

Fig. (1) Representative stereoscopic photographs (X30) showing gutta-percha remnant distribution over root canal surface. 


\section{RESULTS}

\section{Cleanliness test results}

The mean values and standard deviation of cleanliness test results measured by remnant (\%) for all groups for radicular region without solvent are summarized in table (1) and Figure (2).

\section{For Neolix file group}

With Carvene; it was found that the difference between regions was statistically non-significant as indicated by ANOVA test $(\mathrm{F}=2.845, \mathrm{P}=0.0756>0.05)$ where (middle $\geq$ cervical $\geq$ apical)

No-solvent; it was found that the difference between regions was statistically non-significant as indicated by ANOVA test $(\mathrm{F}=2.06, \mathrm{P}=0.1464>0.05)$ where (cervical $\geq$ middle $\geq$ apical)

\section{Carvene vs. no-solvent}

Cervical, Middle and Apical regions; it was found that the difference between carvene and no-solvent subgroups was statistically nonsignificant as indicated by paired t-test $(\mathrm{t}=1.9$, $\mathrm{P}=0.0871>0.05),(\mathrm{t}=0.59, \mathrm{P}=0.5694>0.05)$ and $(\mathrm{t}=$

\section{$1.6, \mathrm{P}=0.1393>0.05)$ where (no-solvent $\geq$ carvene)}

\section{For Silk file group}

With carvene; it was found that the difference between regions was statistically significant as indicated by ANOVA test $(\mathrm{F}=4, .14, \mathrm{P}=0.0271>0.05)$ where (middle $\geq$ cervical $>$ apical)

No-solvent; it was found that the difference between regions was statistically non-significant as indicated by ANOVA test $(\mathrm{F}=0.952, \mathrm{P}=0.3986>0.05)$ where (cervical $\geq$ middle $\geq$ apical)

\section{Carvene vs. no-solvent}

Cervical, middle and apical regions; it was found that the difference between Carvene and no-solvent subgroups was statistically nonsignificant as indicated by paired $\mathrm{t}$-test $(\mathrm{t}=0.66$, $\mathrm{P}=0.5241>0.05),(\mathrm{t}=0.16, \mathrm{P}=0.8747>0.05)$ and $(\mathrm{t}=$ $1.45, \mathrm{P}=0.1740>0.05$ ) where (no-solvent $\geq$ Carvene)

\section{Neolix vs. Silk file groups with carvene or not}

Cervical, middle and apical regions; it was found that the difference between Neolix and Silk groups was statistically non-significant where $($ Neolix $\geq$ Silk $)$.

TABLE (1) Remnant area results (Mean values \pm SDs) for both groups as function of radicular region with/ out solvent.

\begin{tabular}{|c|c|c|c|c|c|c|c|}
\hline \multirow{2}{*}{\multicolumn{2}{|c|}{ Variable }} & \multicolumn{3}{|c|}{ Carvene } & \multicolumn{3}{|c|}{ No-solvent } \\
\hline & & Cervical & Middle & Apical & Cervical & Middle & Apical \\
\hline \multirow{2}{*}{ Group } & Neolix & $\begin{array}{c}39.2768 \\
\pm 6.868\end{array}$ & $\begin{array}{c}40.2358 \\
\pm 7.155\end{array}$ & $\begin{array}{c}31.1237 \\
\pm 5.394\end{array}$ & $\begin{array}{c}46.8245 \\
\pm 9.141\end{array}$ & $\begin{array}{c}43.3028 \\
\pm 8.956\end{array}$ & $\begin{array}{c}37.1661 \\
\pm 5.338\end{array}$ \\
\hline & Silk & $\begin{array}{c}36.9425 \\
\pm 7.509\end{array}$ & $\begin{array}{c}37.0149 \\
\pm 6.038\end{array}$ & $\begin{array}{c}27.8860 \\
\pm 3.918\end{array}$ & $\begin{array}{c}40.2519 \\
\pm 8.378\end{array}$ & $\begin{array}{c}37.3021 \\
\pm 8.737\end{array}$ & $\begin{array}{c}33.6996 \\
\pm 8.357\end{array}$ \\
\hline Statistics & Pvalue & $0.6261 \mathrm{~ns}$ & $0.3959 \mathrm{~ns}$ & $0.3189 \mathrm{~ns}$ & $0.2258 \mathrm{~ns}$ & $0.237 \mathrm{~ns}$ & $0.4132 \mathrm{~ns}$ \\
\hline
\end{tabular}




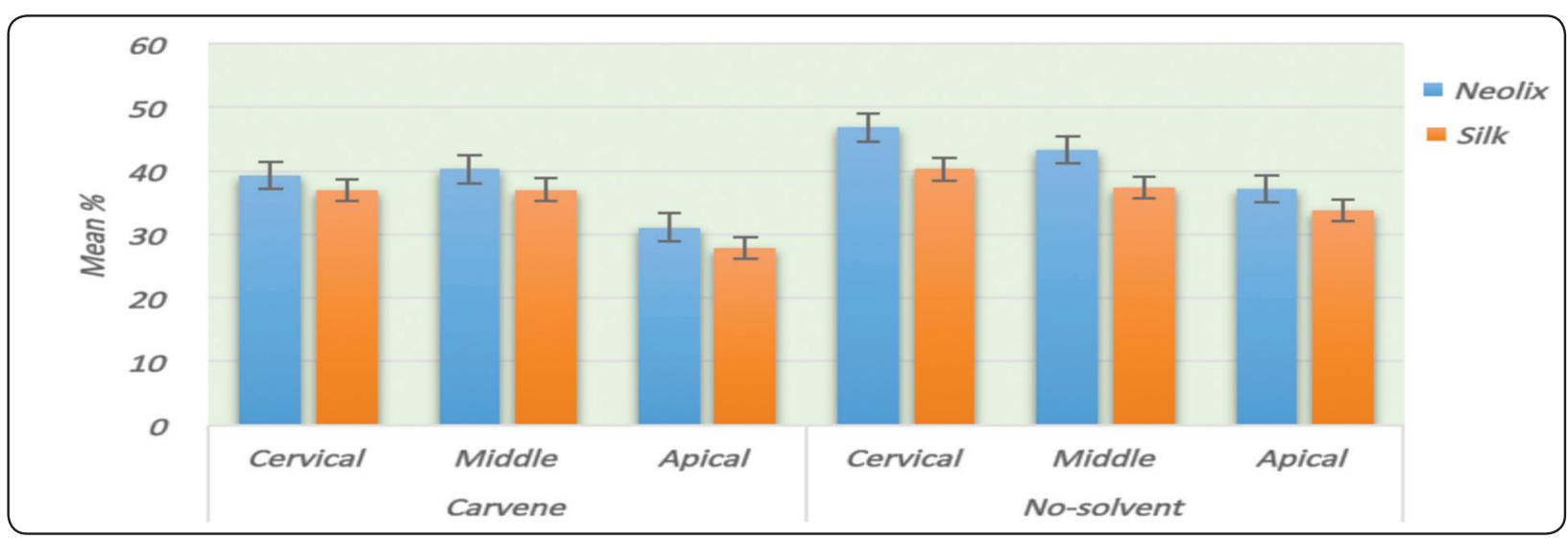

Fig. (2): Column chart of the mean values of remnant area for both file groups as function of radicular region applied with/out solvent.

\section{DISCUSSION}

Vertical sectioning of straight wide root canals to get images of their lumen, together, with the use of the stereomicroscope were recommended to estimate the presence of obturating material remnants ${ }^{(14)}$.

Removal of obturating materials is essential for nonsurgical retreatment. It permits succeeding cleaning, shaping and obturate the root canal system $^{(15)}$. Removal of obturating material covering dentinal tubules looks to be critical so as to reveal bacteria that might be the cause of post-treatment disease. Also, remnants of obturating materials might decrease adhesion and adaptation of cements used for posts and sealers ${ }^{(16)}$.

The additional instruments are directed to improve the root canal preparation, mainly in the apical third ${ }^{(17)}$.

The use of carvene as a solvent in the present study led to gutta percha and sealer residue on the canal walls. The reason for residual gutta percha and sealer could be attributed to the solvents ability to soften gutta percha and modify its structure to a viscous and highly adhesive material, which makes it more difficult to remove ${ }^{(18)}$.

In our study, Neolix file system recorded higher cleanliness than Silk file system. This may be due to the fact that Neolix has completely different manufacturing process from other NiTi rotary systems and it confers very high flexibility with high microhardness. Grouping of these characteristics with a rectangular-shaped cross-section and cutting blades results in high cutting efficacy ${ }^{(19)}$.

Mani Silk is NiTi alloy of martensitic type makes the file more flexible to accommodate the stress. The constant taper throughout the file length with noncutting tip cross-section is teardrop shaped decrease their touching with the canal walls. This could be the major cause for more obturating material remnants located coronally ${ }^{(20)}$.

The tested techniques were not able to completely remove the obturating material. This is in accordance with previous studies ${ }^{(5,21-23)}$.

\section{CONCLUSION}

Neolix file system recorded higher cleanliness than Silk file system with statistically significant difference. Treatment with no-solvent recorded higher cleanliness than with using Carvene with statistically significant difference. Cervical region recorded the highest cleanliness followed by middle region while the lowest cleanliness was recorded with apical region. The difference between radicular regions subgroups was statistically significant. 


\section{REFERENCES}

1. Kasam $\mathrm{S}$ and Mariswamy AB: Efficacy of different methods for removing root canal filling material in retreatment - an in-vitro study. JCDR. 2016, 10: 6-10.

2. Yeter KY, Evcil MS, Ayranci LB and Ersoy I: Weight of apically extruded debris following use of two canal instrumentation techniques and two designs of irrigation needles. Int Endod J. 2013, 46: 795-9.

3. Das S, De Ida A, Das S, Nair V, Saha N and Chattopadhyay $\mathrm{S}$ : Comparative evaluation of three different rotary instrumentation systems for removal of gutta-percha from root canal during endodontic retreatment: An in vitro study. J Conserv Dent. 2017, 20: 311-6.

4. Imura N, Zuolo ML, Ferreira MO and Novo NF: Effectiveness of the canal finder and hand instrumentation in removal of gutta-percha root fillings during root canal retreatment. Int Endod J. 1996, 29: 382-6.

5. Schirrmeister JF, Hermanns P, Meyer KM, Goetz F and Hellwig E: Detectability of residual Epiphany and gutta-percha after root canal retreatment using a dental operating microscope and radiographs--an ex vivo study Int Endod J. 2006, 39: 558- 65.

6. Ladley RW, Campbell AD, Hicks ML and Li SH: Effectiveness of halothane used with ultrasonic or hand instrumentation to remove gutta-percha from the root canal. $\mathrm{J}$ Endod. 1991, 17: 221- 4.

7. Farge, $\mathrm{P}, \mathrm{Nahas} \mathrm{P}$ and Bonin $\mathrm{P}$ : In vitro study of $\mathrm{Nd}$ : YAP laser in endodontic retreatment. J Endod. 1998, 24: 359- 63 .

8. Wolcott JF, Himel VT and Hicks ML: Thermafil retreatment using a new "System B" technique or a solvent. J Endod. 1999, 25: 761- 4.

9. Imura N, Kato AS, Hata GI, Uemura M, Toda T, Weine F: A comparison of the relative efficacy of four hand and rotary instrumentation techniques during endodontic retreatment. Int Endod J. 2000, 33: 361- 6.

10. Hülsmann M. and Bluhm V: Efficacy, cleaning ability and safety of different rotary NiTi instruments in root canal retreatment. Int Endod J. 2004, 37: 468-76.

11. Khoshbin E, Donyavi Z, Abbasi Atibeh E, Roshanaei G, Amani F: The effect of canal preparation with four different rotary systems on formation of dentinal cracks: An in vitro evaluation. Iran Endod J. 2018, 13: 163-8.

12. Pansheriya E, Goel M, Gupta KD, Ahuja R, Kaur RD, Garg V: Comparative evaluation of apical transportation and canal centric ability in apical region of newer nickeltitanium file systems using cone-beam computed tomography on extracted molars: An in vitro study. Contemp Clin
Dent. 2018, 9: 215-20

13. Yosefi MH, Mirfakhraei M, Gholamzad F: () in vitro comparison of the effectiveness of chloroform and carvene chemical solvents in retreatment of root canals filled with gutta-percha. YJDR. 2015, 4: 433-42.

14. Ibrahim, L.A, Negm AM and Kataia MM: Efficacy of different techniques used for root canal retreatment. Future Dental Journal, 2018https://doi.org/10.1016/j. fdj.2018.04.004

15. Bhagavaldas M C, Diwan A, Kusumvalli S, Pasha S, Devale M. and Chava DC.: Efficacy of two rotary retreatment systems in removing Gutta-percha and sealer during endodontic retreatment with or without solvent: A comparative in vitro study. J Conserv Dent: 2017: 20: 12-16.

16. Hunter, KR, Doblecki, W and Pelleu, GB: Halothane and eucalyptol as alternatives to chloroform for softening gutta-percha. J Endod. 1991, 17: 310- 1.

17. Marques da Silva B, Baratto-Filho F, Leonardi DP, Henrique Borges A, Volpato L and Branco Barletta F.: Effectiveness of ProTaper, D-RaCe, and Mtwo retreatment files with and without supplementary instruments in the removal of root canal filling material. Int Endod J. 2012, 45:927-32.

18. Horvath SD, Altenburger MJ, Naumann M, Wolkewitz M, and Schirrmeister JF.: Cleanliness of dentinal tubules following gutta-percha removal with and without solvents: a scanning electron microscopic study. Int Endod J. 2009, 42: $1032-8$.

19. Khoshbin E, Shokri A, Donyavi Z, Shahriari S, Salehimehr G, Farhadian M and Kavandi Z: Comparison of the root canal debridement ability of two single file systems with a conventional multiple rotary system in long oval-shaped root canals: In vitro study. J Clin Exp Dent. 2017, 9: 93944.

20. Shim KS, Soram Oh, Kum KY, Kim Y, Jee K and Chang SW: Mechanical and Metallurgical Properties of Various Nickel-Titanium Rotary Instruments. Biomed Res Int. 201 7, doi: 10.1155/2017/4528601

21. Ferreira JJ, Rhodes JS and Ford TR: The efficacy of gutta-percha removal using ProFiles. Int Endod J. 2001, 34: $267-74$.

22. De Oliveira DP, Barbizam JV, Trope $\mathrm{M}$ and Teixeira FB: Comparison between gutta-percha and Resilon removal using two different techniques in endodontic retreatment. J Endod. 2006, 32:362- 4

23. Ezzie E, Fleury A, Solomon E, Spears R and He J: Efficacy of retreatment techniques for a resin-based root canal obturation material. J Endod. 2006, 32: 341- 4. 